\title{
CDK4 IVS4-nt40 AA genotype and obesity-associated tumors/cancer in Italians - a case-control study Ramachandran Meenakshisundaram ${ }^{1}$ and Claudia Gragnoli*1,2,3,4,5
}

\author{
Address: ${ }^{1}$ Department of Medicine and Cellular \& Molecular Physiology, Milton S. Hershey Medical Center, Hershey, PA, USA, ${ }^{2}$ Penn State \\ University College of Medicine, Hershey, PA, USA, 3Sbarro Institute for Cancer Research \& Molecular Medicine, Center for Biotechnology, Temple \\ University's College of Science \& Technology, Philadelphia, PA, USA, ${ }^{4}$ Department of Biology, Temple University's College of Science \& \\ Technology, Philadelphia, PA, USA and ${ }^{5}$ Molecular Biology Laboratory, Bios Biotech Multi-Diagnostic Health Center, Rome, Italy \\ Email: Ramachandran Meenakshisundaram - rmsundar_chandran@yahoo.co.in; Claudia Gragnoli* - claudia.gragnoli@gmail.com \\ * Corresponding author
}

Published: 28 March 2009

Journal of Experimental \& Clinical Cancer Research 2009, 28:42 doi:10.1 186/1756-9966-28-42

This article is available from: $h t t p: / / w w w . j e c c r . c o m / c o n t e n t / 28 / / / 42$

(C) 2009 Meenakshisundaram and Gragnoli; licensee BioMed Central Ltd.

This is an Open Access article distributed under the terms of the Creative Commons Attribution License (http://creativecommons.org/licenses/by/2.0), which permits unrestricted use, distribution, and reproduction in any medium, provided the original work is properly cited.
Received: 26 February 2009

Accepted: 28 March 2009

\begin{abstract}
Background: Cell cycle checkpoint regulation is crucial for prevention of tumor in mammalian cells. Cyclin-dependant kinase 4 (CDK4) is important in cell cycle regulation, as it controls the G I$\mathrm{S}$ phase of the cell cycle. CDK4 has potential mitogenic properties through phosphorylation of target proteins. We aimed at identifying a role of CDK4 IVS4-nt40 G $\rightarrow$ A gene variant in benign and/ or malignant tumors and in obesity-associated benign and/or malignant tumors in an Italian adult subject dataset.
\end{abstract}

Methods: We recruited 263 unrelated Italian subjects: 106 subjects had at least one benign tumor and 46 subjects had at least one malignant tumor, while 116 subjects had at least two tumors and/ or cancers. We collected BMI data for $90 \%$ of them: 186 subjects had a $\mathrm{BMI} \geq 30 \mathrm{Kg} / \mathrm{m}^{2}$ and 52 subjects had a BMI $\geq 30 \mathrm{Kg} / \mathrm{m}^{2}$. We performed statistical power calculations in our datasets. DNA samples were directly sequenced with specific primers for the CDK4 IVS4-nt40 G $\rightarrow A$ variant. Genotype association tests with disease were performed.

Results: In our study, no significant association of the CDK4 IVS4-nt40 AA genotype with cancer and/or tumors/cancer are/is detected. However, the CDK4 IVS4-nt40 AA genotype is significantly associated with cancer and tumors/cancer in obese patients.

Conclusion: This finding is interesting since obesity is a risk factor for tumors and cancer. This study should prompt further work aiming at establishing the role of CDK4 in contributing to tumor/ cancer genetic risk predisposition, as well as its role as a potentially effective therapeutic target gene for obesity-associated tumor/cancer management.

\section{Introduction}

Cell cycle checkpoint functions regulate cell cycle progression and proliferation. Defects of cell cycle control are one among hallmarks of tumor development and may have relevance in tumor predisposition [1]. Cyclin-dependant kinase $4(C D K 4)$ is an important gene for cell cycle regu- lation, as it determines the number of cells entering the G1 phase cell cycle [2]. It is located on chromosome $12 q 14$ and the protein encoded within this gene is a member of Ser/Thr protein kinase family. CDK4 has mitogenic [2] through phosphorylation of target proteins [4]. The chromosome $12 \mathrm{q} 12-\mathrm{q} 14$ region has been shown by a 
genome scan to be in linkage to bladder cancer [5], as well as to obesity-associated type 2 diabetes genes [6]. Previous studies have reported differential CDK4 expression in tumors such as gliosarcoma, mantle cell lymphoma and squamous cell carcinoma [7-9]. However, no study has up to date investigated the CDK4 variant in the human genome of cancer patients to prove their potential role in oncogenic pathogenesis.

This study was carried out to find out whether there is any association of CDK4 IVS4-nt40 G $\rightarrow$ A SNP with cancer and/or tumors/cancer as well as with obesity-associated cancer and/or tumors/cancer in the Italian population.

\section{Materials and methods}

We recruited from Italy a total of 263 unrelated adult subjects from the general population. We carried out the study with the written informed consent from each subject and with the approval from the Institutional Review Board, in accordance with the Helsinki Declaration guidelines. We collected clinical information on the presence or absence of tumors and/or cancer on the total 263 subjects. Among 263 subjects, 152 subjects (58\%) presented with either benign and/or malignant tumors: among these, 106 subjects had at least one benign tumor and 46 subjects had at least one malignant tumor, while 116 subjects had at least two tumors and/or cancer. The various tumor and cancer types are described in Table 1.

In the subject group, we collected BMI data for $90 \%$ of subjects: 186 subjects had a BMI less than $30 \mathrm{Kg} / \mathrm{m}^{2}$ and

Table I: Number of tumors/cancers types

\begin{tabular}{lcc}
\hline Site & Tumor & Cancer \\
\hline Skin & 1 & 6 \\
\hline Oral cavity & 1 & 1 \\
\hline RT including lungs & 2 & 2 \\
\hline GIT & 8 & 8 \\
\hline Hormonal & 67 & 22 \\
\hline Thyroid & 29 & 1 \\
\hline Hematological & 1 & 5 \\
\hline Brain & 3 & 1 \\
\hline Endocrine & 2 & 0
\end{tabular}

$\mathrm{RT}=$ Respiratory tract, GIT = Gastrointestinal tract (liver, colon and pancreas), Hormonal-dependent $=$ Breast, Ovary, Uterus, Prostate
52 subjects had a $\mathrm{BMI} \geq 30 \mathrm{Kg} / \mathrm{m}^{2}$, thus the latter met the definition for obesity.

DNA samples were directly sequenced by PCR and automated fluorescence sequencer with specific primers for the CDK4 IVS4-nt40 $\mathrm{G} \rightarrow \mathrm{A}$ single nucleotide polymorphism (SNP).

True detectable odds ratios (ORs) for genotype association tests were calculated in our datasets with statistical power at least $60 \%$, type 1 error probability of 0.05 , and given, in the general Italian population, a cancer prevalence of $2.7 \%$ [10] and, in the obese Italian population, of $3.2 \%$ [11] (Table 2).

We tested the CDK4 IVS4-nt40 G $\rightarrow$ A SNP alleles for departure from Hardy-Weinberg equilibrium (HWE) in our cases (positive cancer and/or tumors/cancer) and control subjects (with no cancer and no tumors/cancer) groups, separately, by using Chi-Square test statistics.

With the Mantel-Haenszel algorithm, we tested the CDK4 IVS4-nt40 G $\rightarrow$ A genotype variant for association with cancer and with tumors/cancer against control subjects with no cancer and no tumors/cancer, respectively. We further tested the CDK4 IVS4-nt40 G $\rightarrow$ A at genotype level for association with obesity-associated cancer and with obesity-associated tumors/cancer against non-obese control subjects with no cancer and no tumors/cancer, respectively.

We also perfomed an association test for non-obese cancer and tumors/cancer cases.

\section{Results}

All alleles tested in each group of the four datasets were not in departure from HWE.

We did not identify in our dataset any significant and valid association of the CDK4 IVS4-nt40 G $\rightarrow$ A genotype variant with either cancer or tumors/cancer against control subjects with no cancer and no tumors/cancer, respec-

Table 2: Statistical power calculated for genotype association test in each case-control dataset with $\alpha=0.05$

\begin{tabular}{lcc}
\hline Subject groups & Power & Detectable OR \\
\hline 46 cases and 204 control subjects & $65 \%$ & 4.435 \\
\hline 152 cases and III control subjects & $65 \%$ & 4.400 \\
\hline 10 cases and I78 control subjects & $65 \%$ & 7.975 \\
\hline 23 cases and 89 control subjects & $60 \%$ & 5.725 \\
\hline
\end{tabular}

OR = odds ratio 
tively (Table 3, 4). However, our dataset may not be able to detect any risk variant with a modest effect contributing to cancer and/or tumors/cancer.

In the subset of the obesity-associated tumor/cancer analysis, we identified a significant association of the CDK4 IVS4-nt40 AA genotype with $\mathrm{BMI} \geq 30$ and cancer $(\mathrm{P}=$ 0.002 , Table 5), and with $\mathrm{BMI} \geq 30$ and tumors/cancer (P $=0.007$, Table 6). We had in our datasets of genotype association tests with the obesity-associated cancer and obesity-associated tumors/cancer at least $60 \%$ power to detect the identified risk ORs identified (Table 2). The analysis performed to exclude association of the CDK4 IVS4-nt40 AA genotype with the subset of non-obese cancer and tumors/cancer was not significant (data not shown).

\section{Discussion}

CDK4 is the catalytic subunit of the cyclin D-CDK holoenzyme. The kinase activity of this complex is induced in response to extracellular signals, including growth factors, and it translates signals from the extracellular environment into cell cycle activation. The CDK4 gene lies in a chromosomal region of interest for cancer predisposition [4] and for obesity-associated T2D genes [5]. It is known to be involved in cell cycle regulation, and represents a strong candidate gene for tumor and/or cancer genetic predisposition [6-8]. Although the effect size of any potential gene risk variant in any tumor/cancer is not predictable until is tested, we can deduct from the present study that the CDK4 IVS4-nt40 AA genotype does not independently and significantly contribute as a major significant risk variant to tumors/cancer in our Italian dataset. If there is any CDK4 variant risk effect in tumor and/ or cancer predisposition, it is likely too modest to be detected in the current dataset. It is possible, however, that other CDK4 gene variants may potentially contribute to tumor/cancer risk predisposition as well as that any potential CDK4 variant association may be detected by using a larger dataset.
On the contrary, it should also be considered that the tumor/cancer risk predisposition may be linked to the obesity-factor. In fact, in our study, obese patients (BMI $\geq$ 30) with CDK4 IVS4-nt40AA genotype have a significant increased risk for cancer and tumors/cancer, in both datasets tested. As we excluded any association of the CDK4 IVS4-nt40 AA genotype with the subset of non-obese cancer and tumor/cancer cases, we were able to further confirm the validity of the identified association with the obese-associated cancer and tumor/cancer cases.

Several studies report that obesity increases tumor/cancer incidence [10-12]. From our study, we may conclude that CDK4 IVS4-nt40 AA genotype plays a role in obesity-associated tumor/cancer risk predisposition. However, more studies are warranted to establish the role of other CDK4 variants in tumor-cancer predisposition [4]. As obesity is a preventable associated factor in several tumor and/or cancer types [10-12], both lifestyle modification and genetic screening for obesity-associated tumor/cancer gene risk variants should be implemented to prevent tumors and cancer in patients.

\section{Competing interests}

The authors declare that they have no competing interests.

\section{Authors' contributions}

CG participated in study design, DNA amplification, sequence reading, project coordination and manuscript drafting and revising. RM carried out the statistical analysis, reference collection, and manuscript drafting. All authors have read and approved the manuscript.

\section{Acknowledgements}

Special thanks go to the Molecular Biology staff of Bios Biotech Multi-Diagnostic Health Center (Rome, Italy), which has provided technical as well as financial support for this study.

This study was made possible by the Penn State University Physician-Scientist Stimulus Award and by the Dean's Pilot and Feasibility Grant, number DIBTH0632I-0I from the Office for the Advancement of Telehealth (OAT), Health Resources and Services Administration, DHHS. This project is funded, in part, under a grant from the Pennsylvania Department of

Table 3: CDK4 IVS4-nt40G $\rightarrow$ A genotype association with cancer

\begin{tabular}{lccccccccc}
\hline Genotype & \multicolumn{2}{c}{ 46 cancer } & \multicolumn{2}{c}{ 204 No cancer } & & $\mathbf{X}^{2}$ & 2-t P & OR & 95\% C.I. \\
\cline { 2 - 8 } & + & - & + & & - & & & \\
\hline AA & 7 & 39 & 14 & 190 & 3.405 & 0.060 & 2.44 & $0.83-7.00$ \\
\hline AG & 20 & 26 & 76 & 128 & 0.615 & 0.433 & 1.30 & $0.64-2.60$ \\
\hline GG & 19 & 27 & 114 & 90 & 3.204 & 0.073 & 0.56 & $0.28-1.11$ \\
\hline
\end{tabular}

$\mathrm{X}^{2}=$ Chi-Square, 2 -t $\mathrm{P}=$ 2-tailed $\mathrm{P}$-value, $\mathrm{OR}=$ odds ratio, $\mathrm{C} . \mathrm{I}$. = confidence interval 
Table 4: CDK4 IVS4-nt40G $\rightarrow$ A genotype association with tumor/cancer

\begin{tabular}{lcccccccc}
\hline Genotype & \multicolumn{1}{l}{ I52 Tumor/cancer } & III No tumor/cancer & $\mathbf{X}^{2}$ & 2-t P & OR & 95\% C.I. \\
\cline { 2 - 7 } & + & - & + & - & & & \\
\hline AA & 19 & 133 & 6 & 105 & 3.754 & 0.053 & 2.50 & $0.90-7.28$ \\
\hline AG & 57 & 95 & 52 & 59 & 2.309 & 0.129 & 0.68 & $0.40-1.15$ \\
\hline GG & 76 & 76 & 53 & 58 & 0.130 & 0.718 & 1.09 & $0.65-1.84$ \\
\hline
\end{tabular}

$\mathrm{X}^{2}=$ Chi-Square, 2 -t $\mathrm{P}=$ 2-tailed $\mathrm{P}$-value, $\mathrm{OR}=$ odds ratio, $\mathrm{C} . \mathrm{I}$. = confidence interval

Table 5: CDK4 IVS4-nt40G $\rightarrow$ A genotype association with cancer and $B M I \geq 30$

\begin{tabular}{|c|c|c|c|c|c|c|c|c|}
\hline \multirow[t]{2}{*}{ Genotype } & \multicolumn{2}{|c|}{10 Cancer and $\mathrm{BMI} \geq \mathbf{3 0}$} & \multicolumn{2}{|c|}{ I78 No cancer and BMI $<30$} & \multirow[t]{2}{*}{$x^{2}$} & \multirow[t]{2}{*}{ 2-t P } & \multirow[t]{2}{*}{ OR } & \multirow[t]{2}{*}{ 95\% C.I. } \\
\hline & + & - & + & - & & & & \\
\hline AA & 3 & 7 & 9 & 169 & 9.858 & 0.002 & 8.05 & $1.37-44.21$ \\
\hline AG & 2 & 8 & 66 & 112 & 1.196 & 0.274 & 0.42 & $0.06-2.25$ \\
\hline GG & 5 & 5 & 103 & 75 & 0.240 & 0.624 & 0.73 & $0.17-3.03$ \\
\hline
\end{tabular}

$\mathrm{BMI}=$ body mass index, $\mathrm{X}^{2}=$ Chi-Square, 2 -t $\mathrm{P}=2$-tailed $\mathrm{p}$-value, $\mathrm{OR}=$ odds ratio, $\mathrm{C} . \mathrm{I} .=$ confidence interval

Table 6: CDK4 IVS4-nt40G $\rightarrow$ A genotype association with tumor/cancer and $B M I \geq 30$

\begin{tabular}{|c|c|c|c|c|c|c|c|c|}
\hline \multirow[t]{2}{*}{ Genotype } & \multicolumn{2}{|c|}{23 Tumor/cancer and BMI $\geq 30$} & \multicolumn{2}{|c|}{89 No tumor/cancer and $\mathrm{BMI}<30$} & \multirow[t]{2}{*}{$\mathbf{X}^{2}$} & \multirow[t]{2}{*}{ 2-t P } & \multirow[t]{2}{*}{ OR } & \multirow[t]{2}{*}{ 95\% C.I. } \\
\hline & + & - & + & - & & & & \\
\hline AA & 5 & 18 & 4 & 85 & 7.355 & 0.007 & 5.90 & $1.21-29.82$ \\
\hline AG & 8 & 15 & 35 & 54 & 0.159 & 0.690 & 0.82 & $0.28-2.35$ \\
\hline GG & 10 & 13 & 50 & 39 & 1.185 & 0.276 & 0.60 & $0.22-1.66$ \\
\hline
\end{tabular}

$\mathrm{BMI}=$ body mass index, $\mathrm{X}^{2}=\mathrm{Chi}$-Square, 2 - $\mathrm{P} \mathrm{P}=2$-tailed $\mathrm{P}$-value, $\mathrm{OR}=$ odds ratio, $\mathrm{C} . \mathrm{I}$. = confidence interval

Health using Tobacco Settlement Funds. The Department specifically disclaims responsibility for any analyses, interpretations or conclusions.

\section{References}

I. Ford HL, Pardee AB: Cancer and the cell cycle. J Cell Biochem 1999:166-72.

2. Swenne $I:$ The role of glucose in the in vitro regulation of cell cycle kinetics and proliferation of fetal pancreatic B-cells. Diabetes 1982, 3 I (9):754-60.

3. Bockstaele L, Coulonval K, Kooken H, Paternot S, Roger PP: Regulation of CDK4. Cell Div 2006, I:25.

4. Cozar-Castellano I, Takane KK, Bottino R, Balamurugan AN, Stewart AF: Induction of beta-cell proliferation and retinoblastoma protein phosphorylation in rat and human islets using adenovirus-mediated transfer of cyclin-dependent kinase-4 and cyclin DI. Diabetes 2004, 53(I): 149-59.
5. Ye Y, Yang H, Grossman HB, Dinney C, Wu X, Gu J: Genetic variants in cell cycle control pathway confer susceptibility to bladder cancer. Cancer 2008, I I 2(I I):2467-74.

6. van Tilburg JH, Sandkuijl LA, Franke L, Strengman E, Pearson PL, van Haeften TW, Wijmenga C: Genome-wide screen in obese pedigrees with type 2 diabetes mellitus from a defined Dutch population. Eur J Clin Invest 2003, 33(I 2): 1070-4.

7. Reis RM, Konu-Lebleblicioglu D, Lopes JM, Kleihues $P$, Ohgaki $H$ : Genetic profile of gliosarcomas. Am J Pathol 2000, I 56(2):425-32.

8. Rummel MJ, de Vos S, Hoelzer D, Koeffler HP, Hofmann WK: Altered apoptosis pathways in mantle cell lymphoma. Leuk Lymphoma 2004, 45(I):49-54.

9. Nadal A, Jares P, Pinyol M, Conde L, Romeu C, Fernandez PL, Campo E, Cardesa A: Association of CDK4 and CCNDI mRNA overexpression in laryngeal squamous cell carcinomas occurs without CDK4 amplification. Virchows Arch 2007, 450(2): I6I-7.

10. Micheli A, Francisci S, Krogh V, Rossi AG, Crosignani P: Cancer prevalence in Italian cancer registry areas: the ITAPREVAL 
study. ITAPREVAL Working Group. Tumori 1999, 85(5):309-69.

II. Boru C, Silecchia G, Pecchia A, lacobellis G, Greco F, Rizzello M, Basso N: Prevalence of cancer in Italian obese patients referred for bariatric surgery. Obes Surg 2005, I 5(8): II7I-6.

12. Matsushime H, Roussel MF, Ashmun RA, Sherr C]: Colony-stimulating factor I regulates novel cyclins during the $\mathbf{G I}$ phase of the cell cycle. Cell 199I, 65(4):70I-I3.

13. Rane SG, Dubus P, Mettus RV, Galbreath EJ, Boden G, Reddy EP, Barbacid M: Loss of Cdk4 expression causes insulin-deficient diabetes and Cdk4 activation results in beta-islet cell hyperplasia. Nat Genet 1999, 22(I):44-52.

14. Omata F, Brown WR, Tokuda Y, Takahashi O, Fukui T, Ueno F, Mine $\mathrm{T}$ : Modifiable risk factors for colorectal neoplasms and hyperplastic polyps. Intern Med 2009, 48(3): I23-8.

15. Coyle YM: Lifestyle, genes, and cancer. Methods Mol Biol 2009, 472:25-56.

16. Jordan SJ, Green AC, Whiteman DC, Webb PM: Risk factors for benign serous and mucinous epithelial ovarian tumors. Obstet Gynecol 2007, 109(3):647-54.

Publish with Bio Med Central and every scientist can read your work free of charge

"BioMed Central will be the most significant development for disseminating the results of biomedical research in our lifetime. "

Sir Paul Nurse, Cancer Research UK

Your research papers will be:

- available free of charge to the entire biomedical community

- peer reviewed and published immediately upon acceptance

- cited in PubMed and archived on PubMed Central

- yours - you keep the copyright

Submit your manuscript here:

http://www.biomedcentral.com/info/publishing_adv.asp 